\title{
Fluctuations of sulfate, $S$-bearing amino acids and magnesium in a giant clam shell
}

\author{
T. Yoshimura ${ }^{1, *}$, Y. Tamenori ${ }^{2}$, H. Kawahata ${ }^{1}$, and A. Suzuki ${ }^{3}$ \\ ${ }^{1}$ Atmosphere and Ocean Research Institute, The University of Tokyo, 5-1-5 Kashiwanoha, Kashiwa, Chiba 277-8564, Japan \\ ${ }^{2}$ Japan Synchrotron Radiation Research Institute/SPring-8, 1-1-1 Kouto, Sayo, Hyogo 679-5198, Japan \\ ${ }^{3}$ Geological Survey of Japan, National Institute of Advanced Industrial Science and Technology, Tsukuba Central 7, 1-1-1 \\ Higashi, Tsukuba, Ibaraki 305-8567, Japan \\ *now at: Japan Agency for Marine-Earth Science and Technology 2-15, Natsushima, Yokosuka, Kanagawa, 237-0061, Japan
}

Correspondence to: T. Yoshimura (yoshimurat@jamstec.go.jp)

Received: 9 January 2014 - Published in Biogeosciences Discuss.: 23 January 2014

Revised: 25 May 2014 - Accepted: 14 June 2014 - Published: 24 July 2014

\begin{abstract}
We used micro-X-ray fluorescence combined with X-ray photoabsorption spectroscopy to investigate speciation-specific sulfur profiles in the inner shell layer of a giant clam (Hippopus hippopus). The sulfate, S-bearing amino acids, and total sulfur profiles indicated that inorganic sulfate was the dominant component in the shell of this bivalve. Sulfur profiles in the inner shell layer showed clear annual fluctuations that varied by more than one order of magnitude, from $<50$ to $1420 \mathrm{ppm}$, and sulfate and total sulfur maxima became higher with age, whereas no ontogenetic trend was noticeable in the profile of S-bearing amino acids. A change in the carbonate ion concentration in the calcifying fluid would suggest that an ontogenetic increase in the relative activity of sulfate ions to carbonate ions in the calcifying fluid affects sulfate concentrations in the shells. These results suggest that trace sulfur profiles in the shell of the giant clam may reflect both cyclic shell growth related to environmental factors such as insolation and temperature and ontogenetic changes of the calcifying fluid chemistry mediated by physiological processes. The observed S profile implies a clear change in calcifying fluid chemistry towards less alkaline condition with age. Magnesium fluctuations suggested that $\mathrm{Mg}$ was incorporated into the shells at high growth rates during warm seasons. The spectrum of $\mathrm{Mg} K$-edge X-ray absorption near edge structure (XANES) and comparison of $\mathrm{Mg}$ and S-bearing amino acids profiles indicated that a pronounced effect of the organic fraction or disordered phases were observed in aragonitic shell of $H$. hippopus rather than regulated substitution into the aragonite crystal lattice.
\end{abstract}

\section{Introduction}

The characteristic variations of element profiles in biogenic calcium carbonates are widely used for identifying differences in biological and physicochemical processes associated with element partitioning (Henderson, 2002; Corrège, 2006; Cusack and Freer, 2008). Long-lived bivalves such as reef-dwelling giant clams are geologically important producers of biominerals that provide long-term records (up to $\sim 100$ years) of environmental conditions in tropical and subtropical oceans (e.g., Watanabe et al., 2004; Aubert et al., 2009). Previous studies have analyzed the element profiles of divalent cations and $\mathrm{Sr} / \mathrm{Ca}$ ratios, the primary objective being to evaluate them as environmental proxies (e.g., Elliot et al., 2009; Sano et al., 2012; Yan et al., 2013).

Sulfate is the third most abundant ion in seawater, and sulfur concentrations in biogenic $\mathrm{CaCO}_{3}$ range from several hundred to several thousand parts per million (e.g., Busenberg and Plummer, 1985). To date, however, little attention has been paid to seasonal intrashell sulfur variations. The dynamics of sulfur incorporation into biogenic carbonates is of interest in relation to environmental and physiological parameters (Berry, 1998; Yoshimura et al., 2013a). In the inner shell layer, sulfur shows clear annual first-order fluctuations, with lower sulfur concentrations being associated with periods of faster growth. Thus, trace sulfur profiles in aragonitic shells may reflect cyclic changes of shell growth related to environmental factors that influence shell growth (Yoshimura et al., 2013a). 
Sulfur is an important component of organic compounds, but the chemical form of sulfur in bivalve shells is still poorly understood. The chemical environment of sulfur has been studied in biogenic carbonates (Cuif et al., 2003, 2008; Cusack et al., 2008; Dauphin et al., 2008), and the sulfate concentration in biogenic carbonates has been proposed as an indicator of skeletal organic materials (Lorens and Bender, 1980; Cuif et al., 2003; Takesue et al., 2008), but inorganic sulfate is also present in $\mathrm{CaCO}_{3}$ (e.g., Kitano et al., 1975; Takano, 1985; Kralj et al., 2004; Kontrec et al., 2004). Because of the complexity of organic compounds associated with $\mathrm{CaCO}_{3}$ biomineralization processes (e.g., Cusack and Freer, 2008), both organic and inorganic sulfur potentially contribute to the total sulfur concentration of shell carbonates.

The Mg content of the shell aragonite might also reflect in part biological contamination with organic material and adsorption phenomena during crystal precipitation rather than physicochemically regulated substitution into the aragonite crystal lattice. The $\mathrm{Mg} / \mathrm{Ca}$ profiles of both marine and freshwater aragonitic species show large interspecimen differences with a minor contribution from the variation of ambient environmental factors (e.g., Takesue et al., 2008; Schöne et al., 2010; Izumida et al., 2011), suggesting that the $\mathrm{Mg} / \mathrm{Ca}$ ratios of shell aragonite may reflect biological factors rather than regulated substitution into the aragonite crystal lattice. In a giant clam Tridacna gigas, Elliot et al. (2009) observed seasonal $\mathrm{Mg} / \mathrm{Ca}$ oscillations superimposed on an ontogenetic trend with increasing values and increasing amplitude with age. However, to our knowledge no detailed comparisons regarding the covariation of organic materials with $\mathrm{Mg}$ concentrations in the bivalve shell are available.

X-ray photoabsorption spectroscopy (XAS) is a molecular-scale spectroscopy technique that yields electronic and geometric structural information about the element of interest (Stöhr, 1992). Sulfur and magnesium $K$-edge X-ray absorption near edge structure (XANES) has also been applied to the characterization of the chemical environment (e.g., Pingitore et al., 1995; Morra et al., 1997; Finch and Allison, 2008; Foster et al., 2008; Cusack et al., 2008; Yoshimura et al., 2013a). XAS can be used in combination with $\mathrm{X}$-ray fluorescence with a focused $\mathrm{X}$-ray beam (i.e., micro-X-ray fluorescence; $\mu$-XRF) to determine the speciation-specific spatial element distribution in biogenic carbonates and to generate time series of trace-element profiles in biogenic $\mathrm{CaCO}_{3}$ with high lateral resolution.

In this study, we investigated sulfur and magnesium element profiles in a reef-dwelling clam collected from Ishigakijima, Japan. Our aim was to use $\mu$-XRF/XAS measurements to assess ontogenetic trends in the variability of speciationspecific sulfur and magnesium profiles. Clarification of how sulfur and magnesium are hosted in the shell of a giant clam will provide insight into the mechanisms of minor/trace element incorporation into bivalve shells, and we expect this knowledge to be useful in environmental and biological studies of present and past reef environments.

\section{Materials and methods}

We collected a live specimen of the strawberry clam Hippopus hippopus (Fig. 1) from Ishigaki Island, Japan $\left(24^{\circ} 33^{\prime} \mathrm{N}\right.$, $\left.124^{\circ} 16^{\prime} \mathrm{E}\right)$, which lies in the subtropical northwestern Pacific Ocean (Fig. 1). The average temperature and annual precipitation at the collection site are $24.0^{\circ} \mathrm{C}$ and $2061 \mathrm{~mm}$, respectively (Japan Meteorological Agency; http://www.data. jma.go.jp/obd/stats/etrn/index.php). Hippopus hippopus has an aragonitic shell that consists of an outer and an inner layer (Pätzold et al., 1991). The valves of our specimen were first cut along the maximum growth axis and then sliced into $5 \mathrm{~mm}$ thick slabs with a diamond saw. The cut surfaces were then polished using \#1200, \#2000 and \#6000 3 M imperial polishing paper. The polished slab was cleaned ultrasonically and dried at room temperature.

All X-ray experiments were carried out by using the Bbranch of the soft X-ray photochemistry beamline (BL27SU) at the SPring- 8 synchrotron radiation facility. A twodimensional (2-D) approach was used for partial fluorescence yield measurements in the soft X-ray region (Tamenori et al., 2011). The X-ray beam was focused on a $15 \mu \mathrm{m}$ diameter spot on the sample by Kirkpatrick-Baez mirrors. The photon flux on the focal point was $1 \times 10^{11} \mathrm{Ph} \mathrm{s}^{-1}$ at $2500 \mathrm{eV}$. In the $\mu$-XRF analysis, X-ray fluorescence signals were detected with a single-element silicon drift detector. The sample holder was mounted on a motorized XYZ stage. During analysis, the intensity of the incoming photon beam $\left(I_{0}\right)$ was monitored by measuring the drain current on the surface of a post-focusing mirror. All measurements were performed under vacuum to avoid absorption and scattering of the incident and fluorescent X-rays by air.

The $\mu$-XRF/XAS chemical mapping measurements were made at a fixed excitation energy based on the characteristic resonance peak energies determined by XANES analysis $(2473$ and $2482 \mathrm{eV})$. Total sulfur profiles were obtained at $2600 \mathrm{eV}$, which is $>100 \mathrm{eV}$ above the sulfur $K$-edge energy region. In addition to the $\mu-\mathrm{XRF} / \mathrm{XAS}$ analysis data, full $\mathrm{XRF}$ data were also obtained at each mapping point during the $\mu$-XRF/XAS analysis, and elemental imaging data were extracted from the XRF data set. Although the energy of the excitation X-ray beam was set to the sulfur $K$-edge energy region, all energetically accessible elements were simultaneously excited by the incident photon beam. The element concentrations were calculated by measuring carbonate reference materials JCp-1 and JCt-1, which were obtained from the Geological Survey of Japan (Okai et al., 2004). These reference materials were prepared from a modern coral skeleton (JCp-1) and a Holocene fossil bivalve shell (JCt-1). The relative standard deviation of $\mathrm{S}$ and $\mathrm{Mg}$ signal intensities, based on 10 replicate measurements of carbonate reference 

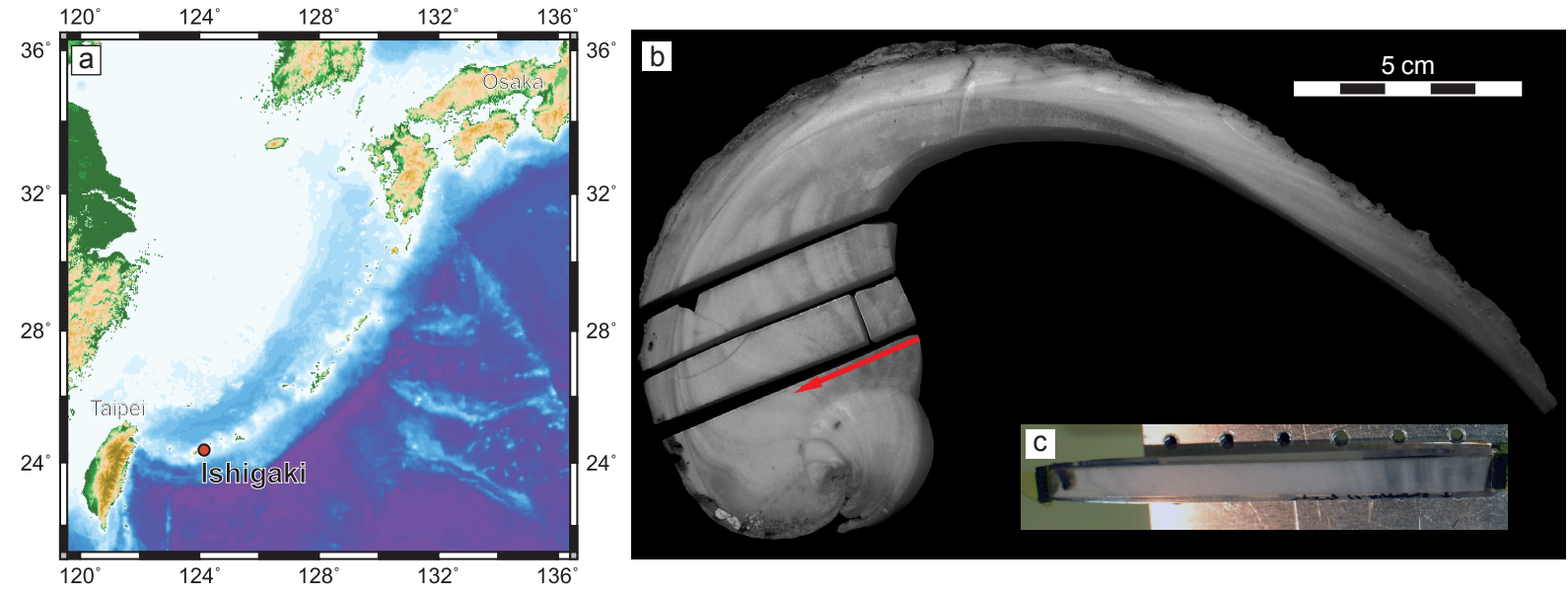

Figure 1. (a) Map of the location of Ishigaki Island, Japan. (b) A slab of the Hippopus hippopus specimen. A polished slab obtained from the inner shell layer was used for $\mu$-XRF/XAS measurements. The red arrow indicates the measurement transect. (c) The polished slab was fixed in an aluminum sample holder with conductive double-sided carbon tape and inserted into the vacuum chamber.
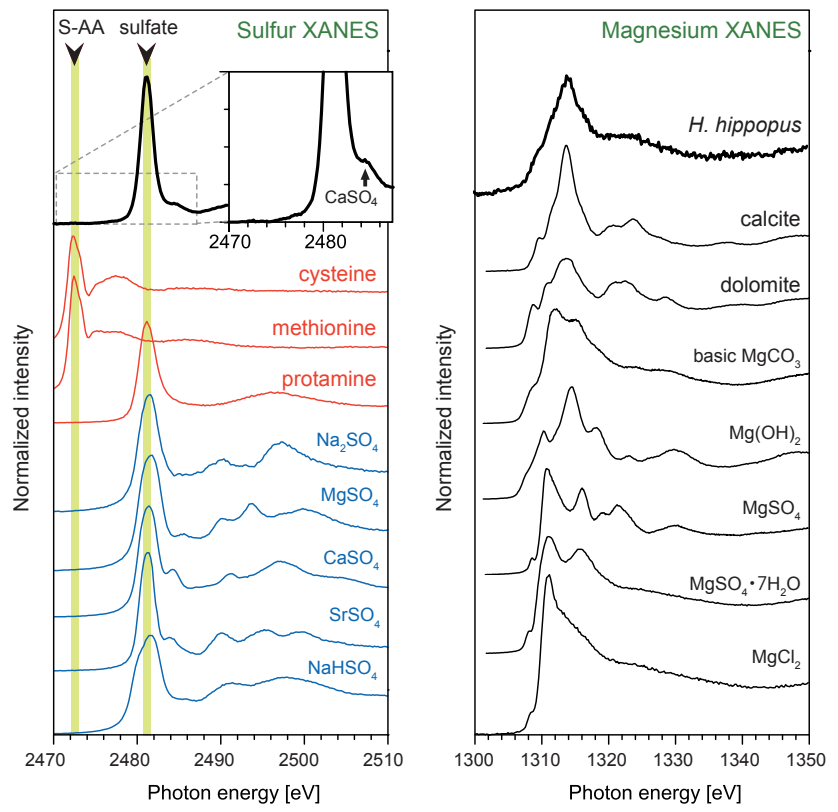

Figure 2. S (left) and $\mathrm{Mg}$ (right) $K$-edge XANES spectra of a giant clam shell aragonite (H. hippopus) and reference materials. MicroXANES of marine clamshell aragonite (H. hippopus) performed at focused mode on points at $\mathrm{S}$ maxima. The XANES spectra have been published previously (Yoshimura et al., 2013a, b). The $\mu$ XRF/XAS measurements were made at a fixed excitation energy based on the characteristic resonance peak energies of S-bearing amino acids $(2473 \mathrm{eV})$ and sulfate $(2482 \mathrm{eV})$.

material JCp-1 with an acquisition time of $1 \mathrm{~s}$ at $2480.0 \mathrm{eV}$, was 1.3 and $2.3 \%$, respectively.

For $\mathrm{Mg} K$-edge XANES measurements, powdered $H$. hippopus shells were fixed with conductive double-sided carbon tape onto an aluminum sample holder. The results

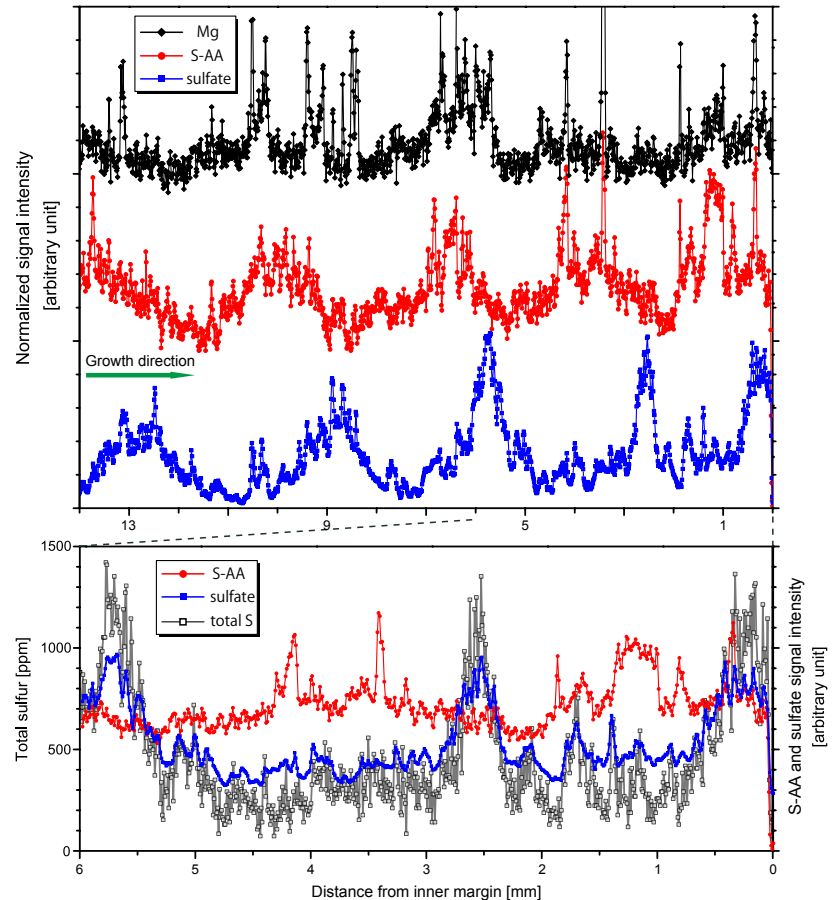

Figure 3. Upper panel: profiles of two different sulfur species, Sbearing amino acids (S-AA, red) and sulfate (blue), and $\mathrm{Mg}$ in the inner shell layer of $H$. hippopus, obtained by the $\mu$-XRF/XAS method at $10 \mu \mathrm{m}$ measurement intervals. Lower panel: total sulfur concentration measured at $8 \mu \mathrm{m}$ intervals compared with sulfur speciation profiles. The cyclic fluctuation of total sulfur correlated well with that of sulfate.

were recorded as fluorescence-yield (FY) spectra with a silicon drift detector (SDD) (Tamenori et al., 2011). The selected energy range for Mg XANES measurements was 
$1300-1350 \mathrm{eV}$ with an energy step of $0.2 \mathrm{eV}$ and an acquisition time of $4 \mathrm{~s}$.

\section{Results and discussion}

\subsection{Sulfur speciation profiles}

The $K$-edge XANES spectra of sulfur exhibit several features that differ among inorganic and organic reference compounds (Fig. 2), and the main peaks of the spectra show large shifts toward higher energies with increasing oxidation state. The main peak of the amino acids cysteine and methionine, which have an $\mathrm{H}-\mathrm{S}-\mathrm{R}$ and an $\mathrm{R}-\mathrm{S}-\mathrm{R}$ bond, respectively, is at around $2473 \mathrm{eV}$. The $\mu-\mathrm{XRF} / \mathrm{XAS}$ mapping result at $2473 \mathrm{eV}$ thus represents an organic sulfur, S-bearing amino acid (S-AA) signal. The XANES spectra of various sulfate compounds exhibit a pronounced peak at around $2482 \mathrm{eV}$ (Fig. 2).

In our specimen, both the S-AA and sulfate profiles exhibited clear cyclic fluctuations, but the phases of the seasonal cycle differed (Fig. 3). The sulfate profile showed a pronounced ontogenetic increase in the amplitude and maximum of each cycle, but no ontogenic trend was observed in the S-AA profile. The lack of a consistent S-AA pattern suggests that temperature and body size had only a minor effect on the amino acid content of the shell of this giant clam. Comparison of the S-AA, sulfate, and total sulfur profiles showed that sulfate and total sulfur (Fig. 3) fluctuated synchronously. Given that inorganic sulfate is the dominant component of the H. hippopus shell (Yoshimura et al., 2013a), the total sulfur profile reflects changes in the concentration of inorganic sulfate. Total sulfur concentrations in the specimen showed pronounced first-order fluctuations that varied by more than one order of magnitude, from $<50$ to $1420 \mathrm{ppm}$ (Fig. 4). Yoshimura et al. (2013a) reported that the annual cycles in sulfur profiles suggest that inorganic sulfate is incorporated into the shell at a higher rate during the winter. On the contrary, the low total sulfur values in aragonitic shells are associated with high shell growth during summer.

The $\mathrm{SO}_{4}^{2-}$ distribution coefficient in abiotic calcite is kinetically controlled, and sulfate incorporation by calcite tends to increase with the calcite precipitation rate (Busenberg and Plummer, 1985); then the sulfur content of biogenic carbonates may thus be proportional to the rate of shell growth. However, in clamshells, sulfate concentration peaks do not correspond to shell growth rate maxima. For this reason, Yoshimura et al. (2013a) proposed that there are physiological controls on the calcifying fluid chemistry. The shell growth rate of a giant clam shell is higher when insolation is increased (Watanabe et al., 2004; Aubert et al., 2009). Supplementary sources of nutrients from symbiotic algae may also maintain the characteristic fast growth of tropical clamshells. Translocated photosynthates produced by zooxanthellae by phototrophy are the most important source of

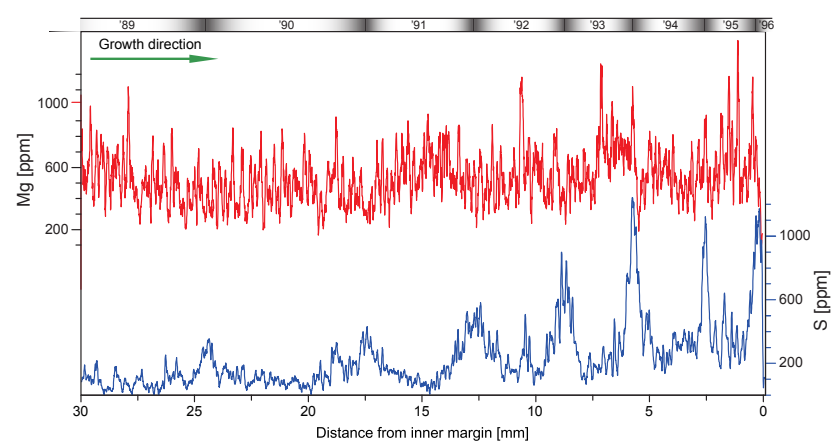

Figure 4. Changes in the moving average trends (15-point smoothing window) of magnesium and total sulfur in the inner shell layer of $H$. hippopus, obtained by the $\mu$-XRF/XAS method at $8 \mu \mathrm{m}$ intervals. The spatial resolution of $\mu$-XRF allows the variations of the $\mathrm{Mg}$ and $\mathrm{S}$ content to be examined at a daily timescale (300-850 points per year).

energy in clams; this source provides sufficient carbon for the growth and metabolic requirements of giant clams (e.g., Klumpp and Griffiths, 1994). Because higher insolation during summer promotes higher rates of photosynthesis by symbiotic algae, enhanced nutrient production may partly explain the high summer growth rates of clamshells (Watanabe and Oba, 1999). During periods of faster growth, the concentration of carbonate ions $\left(\mathrm{CO}_{3}^{2-}\right)$ in calcifying fluids is increased and, at the same time, the increased calcium carbonate saturation state induces higher calcification rates.

Total sulfur profile showed a clear ontogenetic increase in the $\mathrm{S}$ maximum of each cycle, whereas the shell thickening rate of $H$. hippopus decreased as the clam became older (Fig. 4). Because the S content increased with age, we inferred that the sulfate content of the H. hippopus shell is governed primarily by physiological controls on the calcifying fluid chemistry. A positive correlation between the seasonal skeletal growth rate and changes in the carbonate ion concentration in the calcifying fluid would suggest that an ontogenetic increase in the relative activity of sulfate ions to carbonate ions in the calcifying fluid affects sulfate concentrations in the shells. Decreases in $\mathrm{CO}_{3}^{2-}$ concentrations with age, corresponding to lower growth rates at older ages, would positively influence sulfate incorporation into $\mathrm{CaCO}_{3}$ by increasing the relative activity of sulfate ions to carbonate ions in the calcifying fluid. These results imply a clear change in calcifying fluid chemistry towards less alkaline conditions with age. Therefore, the ontogenetic effect in the S profiles of the shell of the giant clam may be due to changes in the relative ionic strength of sulfate and carbonate ions. To determine the $\mathrm{CO}_{3}^{2-}$ concentration, the state of aqueous carbonate system can be constrained by parameters, $\mathrm{pH}$, total alkalinity and dissolved inorganic carbon. The $\mathrm{pH}$ proxies of extrapallial fluid such as boron isotope ratio (Heinemann et al., 2012) would give further information to justify the ontogenetic change of calcifying fluid chemistry. Since the presence 
of $\mathrm{SO}_{4}^{2-}$ in a fluid is known to inhibit $\mathrm{CaCO}_{3}$ crystal growth (Busenberg and Plummer, 1985), a giant clam may try to reduce the $\mathrm{SO}_{4}^{2-}$ in calcifying solutions to facilitate rapid calcification especially during young age.

Interpretations relating the mode of shell growth to environmental and physiological changes have focused on the total sulfur concentration. Large seasonal and ontogenetic changes in shell sulfur concentrations may record cyclic changes in the calcifying fluid chemistry; these changes may be related to environmental factors (e.g., insolation and temperature) as well as to ontogenetic changes in bivalve physiology and individual variability of shell growth. The results of our speciation-specific analysis suggest that bivalve shells can serve as archives of aqueous chemistry of calcifying fluids. Moreover, these results suggest that sulfate concentrations would be a useful proxy for evaluating the response of calcifying fluid chemistry to ocean acidification.

\subsection{Magnesium chemical environment and profile}

The stacked spectra of $H$. hippopus and Mg-bearing compounds are shown in Fig. 2. The most pronounced peaks were at around $1313 \mathrm{eV}$ for $H$. hippopus shell aragonite and other carbonates, calcite and dolomite (Fig. 2). For reference materials, some peaks were evident in the post-edge region. However, the overall shape of the Mg-XANES spectrum for $H$. hippopus was featureless (Fig. 2), which arises either from the organic materials or the highly disordered phase (Finch and Allison, 2008; Foster et al., 2008). XANES results did not permit us to discriminate between organic and disordered Mg phase in aragonitic shells.

Magnesium profiles showed a relatively irregular pattern and higher frequency of periodicity than the sulfur profile (Fig. 3 and 4). Mg concentrations in the specimen varied from 150 to $>1000 \mathrm{ppm}$, and it tended to be somewhat higher at low sulfur concentrations during high growth seasons (Fig. 4). This is consistent with earlier findings that $\mathrm{Mg} / \mathrm{Ca}$ ratios of inner layer of $T$. gigas are inversely correlated with the oxygen isotope profile and thus positively correlated with temperature (Elliot et al., 2009). Moreover, the $\mathrm{Mg}$ fluctuations are to some extent correlated with S-AA (Fig. 3). A positive correlation was found between $\mathrm{Mg}$ and SAA (correlation coefficient $r=0.400, p<0.001$, Student's $t$ test). The incorporation of Mg into aragonitic shells could be interpreted as the result of the influence of biologically mediated controls.

The distribution of organic matrices across the shell has been proposed as the controlling factor responsible for the large annual fluctuation of magnesium. Foster et al. (2008) found that the highest $\mathrm{Mg} / \mathrm{Ca}$ ratios of Arctica islandica were typically present in the annual growth bands, and that $\mathrm{Mg} / \mathrm{Ca}$ variations among growth bands were not significant in most specimens. Moreover, Mg-XANES studies reported that $\mathrm{Mg}$ in biogenic aragonite is not incorporated into the aragonite crystal lattice but instead occurs, inter alia, in or- ganic material, disordered phases, and amorphous $\mathrm{CaCO}_{3}$ (Finch and Allison, 2008; Foster et al., 2008). A large biological control on $\mathrm{Mg}$ incorporation is consistent with earlier findings for other giant clams. For example, the $\mathrm{Mg} / \mathrm{Ca}$ ratios of a giant clam $T$. gigas showed heterogeneous distribution across the different shell layers and seasonal $\mathrm{Mg} / \mathrm{Ca}$ oscillations superimposed on an increasing trend with age (Elliot et al., 2009). In the present case, the distribution patterns of $\mathrm{Mg}$ more plausibly reflect fluctuations of biological controls as previously proposed.

The Mg content of the H. hippopus shell aragonite also reflects in part biological contamination with organic material or adsorption phenomena during crystal precipitation rather than thermodynamic substitution into the aragonite crystal lattice. The discrepancies between Mg and S-AA could be interpreted as the result of the simultaneous influence of inorganically driven controls, such as temperature and growth rate. Because specific functions of organic molecules involved in structural organization and the mode of biomineralization have been proposed, the observed annual Mg fluctuation can have implications for the properties of shell crystallization.

Acknowledgements. We express our appreciation to Naohiko Ohkouchi of Japan Agency for Marine-Earth Science and Technology. We also acknowledge interactive discussions by Maggie Cusack and an anonymous reviewer. This study was conducted with the approval of the SPring- 8 Proposal Review Committee (proposal 2012A1556, 2012B1116 and 2013B1340).

Edited by: D. Gillikin

\section{References}

Aubert, A., Lazareth, C. E., Cabioch, G., Boucher, H., Yamada, T., Iryu, Y., and Farman, R.: The tropical giant clam Hippopus hippopus shell, a new archive of environmental conditions as revealed by sclerochronological and $\delta^{18} \mathrm{O}$ profiles, Coral Reefs, 28, 989-998, 2009.

Berry, J. N.: Sulfate in foraminiferal calcium carbonate: investigating a potential proxy for sea water carbonate ion concentration, Ph.D. Thesis, Massachusetts Institute of Technology, 1998.

Busenberg, E. and Plummer, L. N.: Kinetic and thermodynamic factors controlling the distribution of $\mathrm{SO}_{3}^{2-}$ and $\mathrm{Na}^{+}$in calcites and selected aragonites, Geochim. Cosmochim. Ac., 49, 713-725, 1985.

Corrège, T.: Sea surface temperature and salinity reconstruction from coral geochemical tracers, Palaeogeogr. Palaeocl., 232, 408-428, 2006.

Cuif, J. P., Dauphin, Y., Doucet, J., Salome, M., and Susini, J.: XANES mapping of organic sulfate in three scleractinian coral skeletons, Geochim. Cosmochim. Ac., 67, 75-83, 2003.

Cuif, J. P., Dauphin, Y., Farre, B., Nehrke, G., Nouet, J., and Salomé, M.: Distribution of sulphated polysaccharides within calcareous biominerals suggests a widely shared two-step crystal- 
lization process for the microstructural growth units, Mineral. Mag., 72, 233-237, 2008.

Cusack, M. and Freer, A.: Biomineralization: elemental and organic influence in carbonate systems, Chem. Rev., 108, 4433-4454, 2008.

Cusack, M., Dauphin, Y., Cuif, J. P., Salomé, M., Freer, A., and Yin, H.: Micro-XANES mapping of sulphur and its association with magnesium and phosphorus in the shell of the brachiopod, Terebratulina retusa, Chem. Geol., 253, 172-179, 2008.

Dauphin, Y., Ball, A. D., Cotte, M., Cuif, J. P., Meibom, A., Salomé, M., Susini, J., and Williams, C. T.: Structure and composition of the nacre-prism transition in the shell of Pinctada margaritifera (Mollusca, Bivalvia), Anal. Bioanal. Chem., 309, 1659-1669, 2008.

Elliot, M., Welsh, K., Chilcott, C., McCulloch, M., Chappell, J., and Ayling, B.: Profiles of trace elements and stable isotopes derived from giant long-lived Tridacna gigas bivalves: Potential applications in paleoclimate studies, Palaeogeogr. Palaeocl., 280, 132$142,2009$.

Finch, A. A. and Allison, N.: Mg structural state in coral aragonite and implications for the paleoenvironmental proxy, Geophys. Res. Lett., 35, L08704, doi:10.1029/2008GL033543, 2008.

Foster, L. C., Finch, A. A., Allison, N., Andersson, C., and Clarke, L. J.: $\mathrm{Mg}$ in aragonitic bivalve shells: Seasonal variations and mode of incorporation in Arctica islandica, Chem. Geol., 254, 113-119, 2008.

Heinemann, A., Fietzke, J., Melzner, F., Böhm, F., Thomsen, J., Garbe-Schönberg, D., and Eisenhauer, A.: Conditions of Mytilus edulis extracellular body fluids and shell composition in a $\mathrm{pH}$-treatment experiment: Acid-base status, trace elements and $\delta^{11} \mathrm{~B}$, Geochem. Geophys. Geosys., 13, Q01005, doi:10.1029/2011GC003790, 2012.

Henderson, G. M.: New oceanic proxies for paleoclimate, Earth Planet. Sci. Lett., 203, 1-13, 2002.

Izumida, H., Yoshimura, T., Suzuki, A., Nakashima, R., Ishimura, T., Yasuhara, M., Inamura, A., Shikazono, N., and Kawahata, $\mathrm{H}$.: Biological and water chemistry controls on $\mathrm{Sr} / \mathrm{Ca}, \mathrm{Ba} / \mathrm{Ca}$, $\mathrm{Mg} / \mathrm{Ca}$ and $\delta^{18} \mathrm{O}$ pro?les in freshwater pearl mussel Hyriopsis sp., Palaeogeogr. Palaeocl., 309, 298-308, 2011.

Kitano, Y., Okumura, M., and Idogaki, M.: Incorporation of sodium, chloride and sulfate with calcium carbonate, Geochem. J., 9, 7584, 1975.

Klumpp, D. D. and Griffiths, C. C.: Contributions of phototrophic and heterotrophic nutrition to the metabolic and growth requirements of four species of giant clam (Tridacnidae), Mar. Ecol.Prog. Ser., 115, 103-115, 1994.

Kontrec, J., Kralj, D., Brečević, L., Falini, G., Fermani, S., NoethigLaslo, V., and Mirosavljević, K.: Incorporation of inorganic anions in calcite, Eur. J. Inorg. Chem., 2004, 4579-4585, 2004.

Kralj, D., Kontrec, J., Brečević, L., Falini, G., and Nöthig-Laslo, V.: Effect of inorganic anions on the morphology and structure of magnesium calcite, Chem. Eur. J., 10, 1647-1656, 2004.

Lorens, R. B. and Bender, M. L.: The impact of solution chemistry on Mytilus edulis calcite and aragonite, Geochim. Cosmochim. Ac., 44, 1265-1278, 1980.
Morra, M. J., Fendorf, S. E., and Brown, P. D.: Speciation of sulfur in humic and fulvic acids using X-ray absorption near-edge structure (XANES) spectroscopy, Geochim. Cosmochim. Ac., 61, 683-688, 1997.

Okai, T., Suzuki, A., Terashima, S., Inoue, M., Nohara, M., Kawahata, H., and Imai, N.: Collaborative analysis of GSJ/AIST geochemical reference materials JCp 1 (Coral) and JCt 1 (Giant Clam), Geochemistry, 38, 281-286, 2004 (in Japanese).

Pätzold, J., Heinrichs, J. P., Wolschendorf, K., and Wefer, G.: Correlation of stable oxygen isotope temperature record with light attenuation profiles in reef-dwelling Tridacna shells, Coral Reefs, 10, 65-69, 1991.

Pingitore Jr., N. E., Meitzner, G., and Love, K. M.: Identification of sulfate in natural carbonates by X-ray absorption spectroscopy, Geochim. Cosmochim. Ac., 59, 2477-2483, 1995.

Sano, Y., Kobayashi, S., Shirai, K., Takahata, N., Matsumoto, K., Watanabe, T., Sowa, K., and Iwai, K.: Past daily light cycle recorded in the strontium/calcium ratios of giant clam shells, Nat. Commun., 3, 761, doi:10.1038/ncomms1763, 2012.

Schöne, B. R., Zhang, Z., Jacob, D. E., Gillikin, D. P., Tütken, T., Garbe-Schönberg, D., McConnaughey, T., and Soldati, A.: Effect of organic matrices on the determination of the trace element chemistry $(\mathrm{Mg}, \mathrm{Sr}, \mathrm{Mg} / \mathrm{Ca}, \mathrm{Sr} / \mathrm{Ca})$ of aragonitic bivalve shells (Arctica islandica) - Comparison of ICP-OES and LA-ICP-MS data, Geochem. J., 44, 23-37, 2010.

Stöhr, J.: NEXAFS Spectroscopy, Springer, Berlin, 1992.

Takano, B.: Geochemical implications of sulfate in sedimentary carbonates, Chem. Geol., 49, 393-403, 1985.

Takesue, R. K., Bacon, C. R., and Thompson, J. K.: Influences of organic matter and calcification rate on trace elements in aragonitic estuarine bivalve shells, Geochim. Cosmochim. Ac., 72, 5431-5445, 2008.

Tamenori, Y., Morita, M., and Nakamura, T.: Two-dimensional approach to fluorescence yield XANES measurement using a silicon drift detector, J. Synchrotron Rad., 18, 747-752, 2011.

Watanabe, T. and Oba, T.: Daily reconstruction of water temperature from oxygen isotopic ratios of a modern Tridacna shell using a freezing microtome sampling technique, J. Geophys. Res., 104, 20667-20674, 1999.

Watanabe, T., Suzuki, A., Kawahata, H., Kan, H., and Ogawa, S.: A 60-year isotopic record from a mid-Holocene fossil giant clam (Tridacna gigas) in the Ryukyu Islands: physiological and paleoclimatic implications, Palaeogeogr. Palaeocl., 212, 343-354, 2004.

Yan, H., Shao, D., Wang, Y., and Sun, L.: Sr/Ca profile of long-lived Tridacna gigas bivalves from South China Sea :A new highresolution SST proxy, Geochim. Cosmochim. Ac., 112, 52-65, 2013.

Yoshimura, T., Tamenori, Y., Suzuki, A., Nakashima, R., Iwasaki, N., Hasegawa, H., and Kawahata, H.: Element profile and chemical environment of sulfur in a giant clam shell: insights from $\mu$-XRF and X-ray absorption near-edge structure, Chem. Geol., 352, 170-175, 2013a.

Yoshimura, T., Tamenori, Y., Iwasaki, N., Hasegawa, H., Suzuki, A. and Kawahata, H.: Magnesium $K$-edge XANES spectroscopy of geological standards, J. Synchrotron Rad., 20, 734-740, 2013 b. 